\title{
EVIDENCIAÇÃO DO CAPITAL INTELECTUAL NO RELATO INTEGRADO DE EMPRESAS BRASILEIRAS PARTICIPANTES DE PROGRAMA PILOTO INTERNACIONAL ${ }^{1}$
}

\author{
Nadson Jaime Ferreira Alves \\ Universidade Federal do Pará \\ nadson@ufpa.br \\ Márcia Athayde \\ Universidade da Amazônia \\ athayde.marcia@gmail.com
Ivan Carneiro do Nascimento
Universidade Federal do Pará ivancnasc@hotmail.com \\ Leandro Galvão Croelhas \\ Universidade Federal do Pará \\ leandro.contabilista@yahoo.com.br
}

\begin{abstract}
Resumo
Diante da crescente exigência por uso responsável dos recursos, a comunicação corporativa, por meio do Relato Integrado (RI), avança na busca da efetividade da informação, integrando diferentes conteúdos para evidenciar como a organização cria valor, em linguagem clara, enxuta e útil aos usuários. Desta forma, esta pesquisa objetiva analisar como o capital intelectual (CI) está sendo evidenciado no RI de empresas brasileiras participantes do programa piloto do International Integrated Reporting Council (IIRC), sob os princípios da conectividade, completude, concisão e coerência. Metodologicamente, é uma pesquisa qualitativa, realizada por meio de análise de conteúdo de informações coletadas em 21 Relatos Integrados de sete empresas brasileiras, no período de 2016 a 2018. Os resultados evidenciaram conectividade de informações do próprio relato em todas as empresas, mas falham na conexão aos relatórios específicos (Financeiro, Sustentabilidade, Governança Corporativa e da Administração); no quesito completude, os relatos se apresentam completos, com exceções em valores monetários distintos quanto a cada tipo de investimento; no quesito concisão, há divergências na representatividade do capital intelectual em relação ao total de informações divulgadas; em relação à coerência, todos apresentaram coerência das informações divulgadas em relação a anos anteriores, mas, apenas duas empresas projetam o capital intelectual no futuro. Conclui-se, que todos os relatos cumpriram os requisitos básicos de evidenciação esperados, e descrevem o capital intelectual de forma menos quantitativa (monetária) e mais qualitativa, ainda que alguns sejam mais dispersos que outros, necessitando maior interação com outros relatórios da organização, além da necessidade de evidenciar os planos futuros de gestão do capital intelectual.
\end{abstract}

Palavras-Chave: Capital Intelectual. Contabilidade. Ativos Intangíveis. Relato Integrado.

\footnotetext{
${ }^{1}$ Artigo originalmente apresentado no X Colóquio Organizações, Desenvolvimento e Sustentabilidade - 2019.
} 


\title{
EVIDENCE OF INTELLECTUAL CAPITAL IN THE INTEGRATED REPORT OF BRAZILIAN COMPANIES PARTICIPATING IN AN INTERNATIONAL PILOT PROGRAM
}

\begin{abstract}
In view of the growing demand for responsible use of resources, corporate communication, through the Integrated Reporting (IR), advances in the search for information effectiveness, integrating different contents to show how the organization creates value, in clear, lean and useful language to users. Thus, this research aims to analyze how intellectual capital (IC) is being evidenced in the IR of Brazilian companies participating in the pilot program of the International Integrated Reporting Council (IIRC), under the principles of connectivity, completeness, conciseness and coherence. Methodologically, it is a qualitative research, carried out through content analysis of information collected in 21 Integrated Reports from seven Brazilian companies, in the period from 2016 to 2018. The results showed connectivity of information from the report itself in all companies, but fail to connection to specific reports (Financial, Sustainability, Corporate Governance and Management); in terms of completeness, the reports are complete, with exceptions in different monetary values for each type of investment; regarding conciseness, there are divergences in the representativeness of intellectual capital in relation to the total information disclosed; in relation to coherence, all presented consistency in the information released in relation to previous years, but only two companies project intellectual capital in the future. It is concluded that all reports met the expected basic disclosure requirements, and describe intellectual capital in a less quantitative (monetary) and more qualitative way, although some are more dispersed than others, requiring greater interaction with other reports of the organization, in addition to the need to highlight future plans for managing intellectual capital.
\end{abstract}

Keywords: Intellectual Capital. Accounting. Intangible Asset. Integrated Reporting.

\section{INTRODUÇÃO}

Nas últimas décadas ocorreram mudanças gradativas na forma de estruturação das corporações, fortemente provocadas pelo processo de globalização, auxiliado pelo rápido avanço das tecnologias de produção, de informação e de telecomunicação, com efeito nas novas formas de percepção e interpretação da sociedade como um todo, inclusive na percepção do que seja o processo produtivo (ANTUNES; MARTINS, 2002, 2007a, 2007b).

Essas mudanças gradativas na economia mundial vêm sendo descritas por estudiosos da área como o período de transição de uma sociedade industrial para uma sociedade do conhecimento. Assim, os recursos considerados e valorizados até então na produção (terra, capital e trabalho), demonstram insuficiência na discussão do processo produtivo na atualidade, dada a importância de considerar o conhecimento como recurso essencial e, em algumas situações, determinante. Essa mudança na sociedade transformou a estrutura econômica das nações e, sobretudo, a forma de valorizar o ser humano no processo produtivo, com tais mudanças de percepção tendo reflexos, inclusive, na mensuração do patrimônio feito pela contabilidade (ANTUNES; MARTINS, 2002).

Cabe ressaltar que o objetivo da contabilidade é demonstrar a situação patrimonial das organizações de modo quantificado e qualificado, garantindo que as informações prestadas e/ou publicadas sejam verídicas. Assim, dentre essas mudanças está o conceito e a 


\section{ARTIGO}

INOVAÇÃo

mensuração de ativos intangíveis que, há tempos, se mostra cada vez mais relevante ao valor das organizações (ALVES et al., 2017; ALVES 2017), como é o caso do capital intelectual (CI), conceituado como ativo baseado em conhecimento (IIRC, 2013), e apesar de toda sua subjetividade, dada sua intangibilidade, sua evidenciação é tão importante, ou mais, quando na evidenciação dos ativos tangíveis. Neste contexto de evidenciação dos resultados e da forma como as organizações criam valor para seus stakeholders, como forma de melhorar evidenciação dos diversos capitais (financeiro, humano, manufaturado, intelectual, natural e social) utilizados ou afetados pelas organizações, foi instituído o framework do Relato Integrado (RI), em 2013, pelo IIRC, com o intuito de unir as informações dos relatórios financeiros e não financeiros, sem os substituir (CARVALHO; KASSAI, 2014).

Como parte de seu desenvolvimento foi elaborado um programa piloto, onde as organizações participantes (sendo doze no Brasil), teriam que seguir um framework, que consiste em um manual com objetivos, princípios básicos e conteúdos básicos que devem conter para a elaboração do RI (IIRC, 2013b), o qual objetiva evidenciar a criação de valor baseando nos seguintes capitais: financeiro, intelectual, natural, manufaturado, humano, social e de relacionamento, sendo que o capital intelectual é o conhecimento em posse da empresa e a capacidade de mantê-lo e expandi-lo.

Com base nestes elementos, este estudo apresenta a seguinte questão de pesquisa: como o capital intelectual está sendo evidenciado no Relato Integrado das empresas brasileiras participantes do programa piloto no período de 2016 a 2018? Esta pesquisa objetiva analisar a evidenciação do capital intelectual no RI, sob os princípios da conectividade, da completude, da concisão e da coerência, previstos no framework do RI.

A realização desta pesquisa se justifica porque, uma boa evidenciação, seja ela financeira ou não, auxilia na percepção da sustentabilidade de uma organização e, por conseguinte, na tomada de decisão por parte dos usuários dos relatórios corporativos. E dada a subjetividade dos ativos intangíveis, em especial, o capital intelectual, que se constitui em uma das partes mais relevantes na criação de valor de uma organização, na atualidade (ALVES, 2017), por isso precisa ser bem evidenciado. Dada a relevância da divulgação, pesquisas que retratam a qualidade das informações divulgadas em RI vêm preencher uma lacuna fértil de pesquisas contemporâneas voltadas a área de negócios.

Este artigo está estruturado em cinco seções, além desta introdução; a seção 2 apresenta o referencial teórico, com ênfase ao capital intelectual e aos fundamentos do Relato Integrado; a seção 3 apresenta a metodologia da pesquisa; a seção 4 trata dos resultados e das discussões; e por fim, na seção 5 são apresentadas as considerações finais. 


\section{ARTIGO}

INOVAÇÃo

\section{REFERNCIAL TEÓRICO}

\subsection{ATIVOS INTANGÍVEIS E CAPITAL INTELECTUAL}

É cada vez mais evidente que o final do século XX foi um período crucial para o desenvolvimento da gestão de patrimonial, especialmente agregando valor por outros processos tais como mídia e relacionamento corporativo, o que levou o mundo dos negócios à uma era de incertezas, isso se deve, em parte, pela divergência, cada vez mais marcante, entre o valor patrimonial fornecido pela contabilidade e aquele negociado entre comprador/vendedor de um patrimônio (ANTUNES; MARTINS, 2002; SANTOS et al., 2008; SILVA FILHO; BARBOSA; PEREIRA, 2019) e, em parte, pela dificuldade de identificação dos elementos que estavam influenciando o valor da organização reconhecido pelo mercado. Nesse contexto que surgiram os estudos acerca dos ativos intangíveis e propriamente do capital intelectual.

O início do conceito capital intelectual se deu em 1986 com a publicação do livro The Know-how Company de Sveiby, tal livro publicado na Suécia trazia em si meios de gerenciar ativos intangíveis. Já em 1991, a Skandia, empresa escandinava, com matriz na Suécia, criou, pela primeira vez na história, um cargo de diretor de capital intelectual, essa empresa tem importância até a atualidade na questão de gerenciamento dos relatórios (BONACIM, 2010).

Segundo Antunes e Martins (2002), desde então, o conhecimento aplicado (capital intelectual) vem impactando ainda mais no valor das organizações, uma vez que a materialização da utilização desse recurso, associada às tecnologias de informação disponíveis e agregadas para atuar num ambiente globalizado, produzem benefícios intangíveis que agregam valor às mesmas. Como demonstrado na Figura 1, a participação dos ativos intangíveis no valor nas empresas era de 17\%, em 1975, e cresce acentuadamente chegando a $84 \%$ do valor das empresas em 2015.

Mudanças na percepção da sociedade em relação a criação de valor por parte de uma organização revelam a necessidade de ampliar a consideração de elementos intangíveis nos relatórios corporativos, dada a representatividade desses intangíveis na criação de valor das empresas (ALVES et. al., 2017a; ALVES, 2017b). Empresas como Uber, Ifood e 99 são exemplos de patrimônios essencialmente intangíveis. Isso acarreta a necessidade de aplicação de nova filosofia de administração e novas formas de avaliação do valor da empresa que contemplem o valor do conhecimento (ANTUNES, 2002). 
Figura 1 - Componentes do Valor de Mercado do Índice S\&P 500.

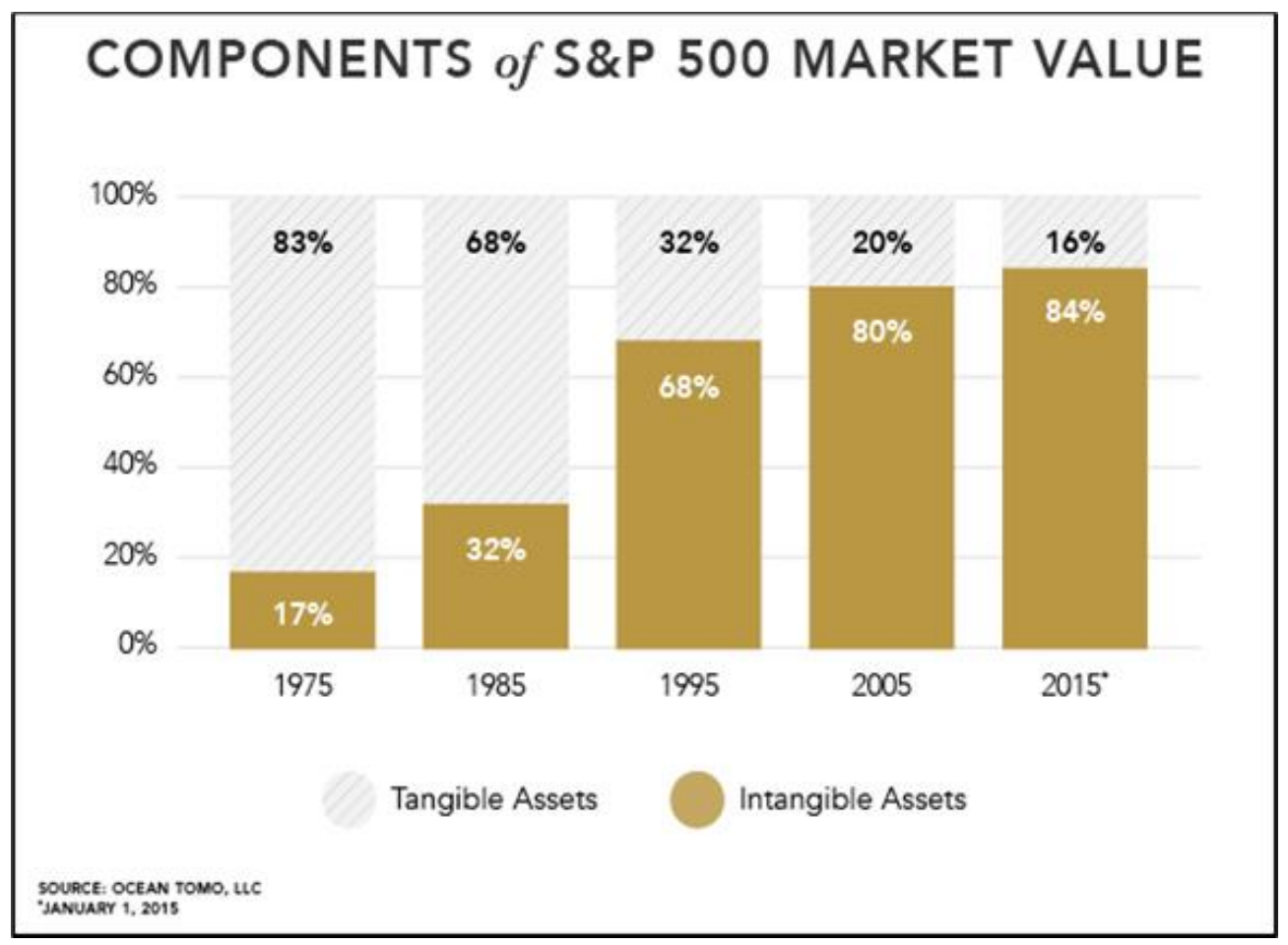

Fonte: Ocean Tomo, 2015.

Segundo Bonacim (2010), o conceito de capital intelectual se divide em dois entendimentos. O primeiro dividido em quatro categorias de ativos: (i) de mercado, (ii) humanos, (iii) de propriedade intelectual e (iv) de infraestrutura. O segundo conceito dividido em 3 categorias: (i) competência dos empregados; (ii) estrutura interna e (iii) estrutura externa.

De acordo com o framework do Relato Integrado, o capital intelectual é composto por (ativos) intangíveis organizacionais baseados em conhecimento, em posse da empresa, bem como a capacidade em saber mantê-los e expandi-los, são de dois tipos: (i) propriedade intelectual, por meio de patentes, direitos autorais, softwares, direitos e licenças; e (ii) capital organizacional, tais como conhecimento tácito, sistemas, procedimentos e protocolos. O que não se confunde com o capital humano, caracterizado pelas competências, capacidades, experiências e motivações dos colaboradores para buscar melhorias contínuas; nem com o capital social e de relacionamento, composto pelas relações entre a organização e a comunidade e outras partes interessadas (IIRC, 2013).

\subsection{RELATO INTEGRADO (RI)}

Ao final de 2009, foi discutida a ideia da criação de uma organização independente, 
com o objetivo de desenvolver uma nova forma de evidenciação corporativa que incluía não somente as questões financeiras como também as não financeiras, além de representar tais informações de forma interligada, compreensível e multidimensional. Assim foi criado o International Integrated Reporting Council (IIRC), em agosto de 2010, para sistematizar o Relato Integrado.

Em 2011 foi apresentado o protótipo com orientações para a elaboração do referido relato. Em 2012 começou um programa, com empresas voluntárias, para testar sua aplicação. Em 2013 foi aberta audiência pública para a contribuição de novas ideias. Em dezembro de 2013, foi publicado framework do RI (ZARO et al., 2014).

O framework do RI é um manual elaborado com a intenção de auxiliar as empresas na criação dos seus relatos, baseados em sete princípios (IIRC, 2013):

- Foco estratégico e orientação para o futuro: um RI deve conter a visão da estratégia da organização e o modo como ela se relaciona com sua capacidade em gerar valor em curto, médio e longo prazo, além do uso dessa capacidade e seu impacto sobre os capitais.

- Conectividade da informação: o RI deve mostrar uma imagem completa da combinação, da interrelação e das dependências entre os diversos fatores que afetam a capacidade de gerar valor ao longo do tempo.

- Relações com partes interessadas: o RI deve evidenciar a relação que a organização tem com seus principais interessados, os stakeholder, incluindo como e até onde ela entende, levam em conta e responde aos anseios desses.

- Materialidade: o RI deve divulgar informações sobre assuntos que afetam, de forma significativa, a geração de valor da organização.

- Concisão: o RI deve ser conter o suficiente para entender a estratégia, a governança, o desempenho e as perspectivas da organização, sem se preocupar com as informações menos relevantes

- Confiabilidade e Completude: o RI deve abranger todos os temas, sejam eles positivos ou não, de maneira equilibrada e sem erros significativos, sendo assim, deve-se ter um controle robusto do sistema interno (confiabilidade) e deve-se evidenciar todas as informações tanto positivas quanto negativas

- Coerência e Comparabilidade: o RI deve conter informações ao longo do tempo de forma lógica (coerência), fazendo assim uma comparação, não apenas em com seus relatórios, mas também com o de outras organizações. 
- Entender o framework do RI foi fundamental para o direcionamento deste estudo, e relativamente simples, ao evidenciar os princípios norteadores, os conteúdos e os tipos de capitais que evidenciam a criação de valor por parte das empresas, em especial, o capital intelectual. Tal documento conceitua o RI como um documento elaborado pelas organizações com objetivo de evidenciar a estratégia, governança, desempenho e perspectiva, da mesma, em seu ambiente externo, que a levam à geração de valor em curto, médio e longo prazo (IIRC, 2013).

Conforme se apresenta na Figura 2, o RI precisa evidenciar a criação de valor baseando nos seguintes capitais: financeiro, intelectual, natural, manufaturado, humano, social e de relacionamento. Sendo que o capital financeiro está voltado para a evidenciação de investimentos, dívidas, e o capital que permitem a organização produzir bens e serviços. Por sua vez, o capital manufaturado se reporta à infraestrutura física que a empresa utiliza, tais como edificações, máquinas e equipamentos. O capital natural revela todos os recursos utilizáveis pela empresa, renováveis e não renováveis. O capital humano se refere às competências, capacidades, experiências e motivações dos colaboradores, enquanto o capital intelectual é o conhecimento em posse da empresa e a capacidade de mantê-lo e expandi-lo. Por fim, o capital social e de relacionamento evidencia a relação entre a empresa e seus stakeholders.

Figura 2 - Tipos de Capitais apresentados no Relato Integrado.

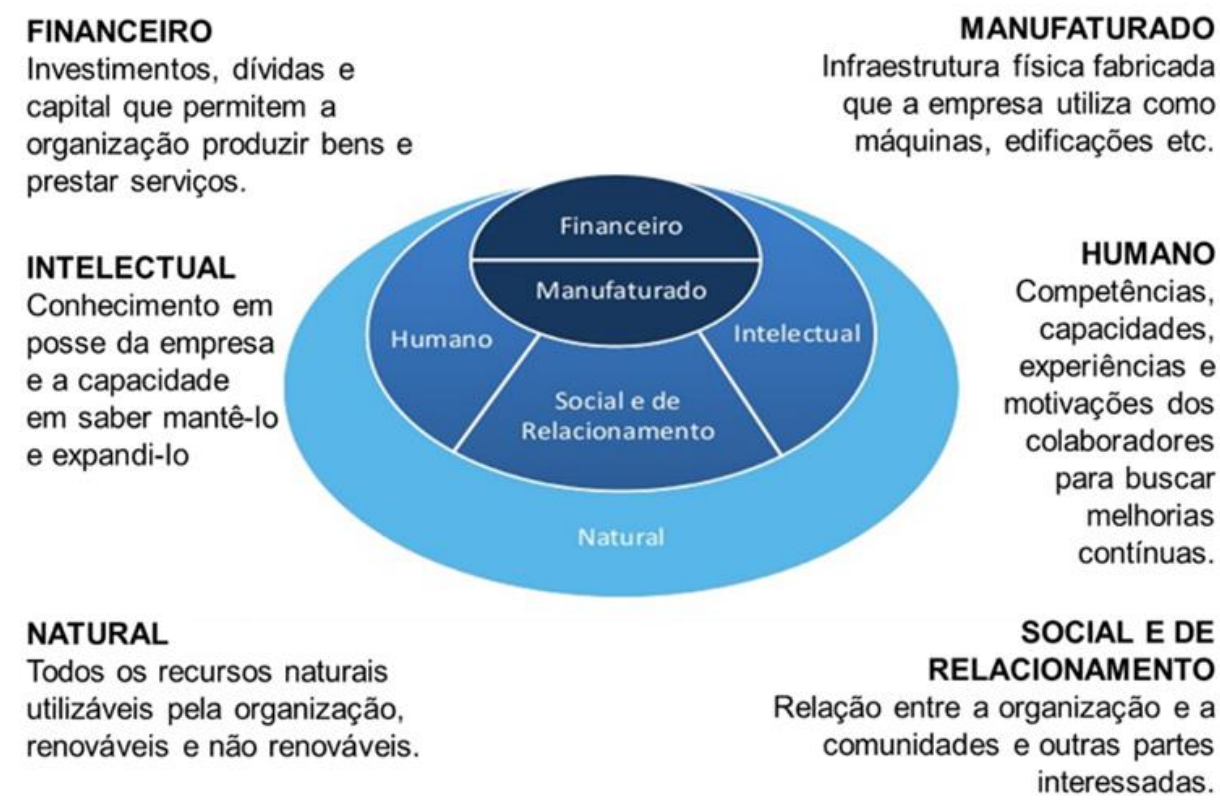

Fonte: Alves, 2017b.

A integração desses capitais nem sempre é tarefa simples, dada a inexperiência das 
corporações em integrar diferentes métricas (financeiras e não-financeiras) para retratar a criação de valor. Até mesmo as empresas de auditoria estão precisando sair de sua zona de conforto, no intuito de assegurar a qualidade de tais informações. Apesar das dificuldades nessa fase de experimentação, há resultados promissores junto a usuários e elaboradores dos RI das empresas do programa piloto, por potencializarem maior alinhamento dos relatos corporativos às demandas dos usuários, por serem relatos mais robustos ao retratarem a sinergia dos diferentes capitais, ao mesmo tempo em que são mais atrativos por serem mais sintéticos e usarem de linguagem visual mais acessível (MACIEL, 2015; ALVES, 2017b).

\section{PROCEDIMENTOS METODOLÓGICOS}

Pesquisa qualitativa, cuja finalidade é relatar os dados de forma interpretativa através dos dados coletados (MARCONI; LAKATOS, 2004), sendo a confecção da pesquisa dividida em cinco etapas: (1) encontrar os RI das empresas piloto dos anos de 2016, 2017 e 2018, em seus respectivos sites; (2) procurar pela evidenciação do capital intelectual (CI) nos RI coletados; (3) fazer uma varredura através de palavras-chave, para saber se havia alguma outra referência ao capital intelectual e se ele interagia com outros capitais, procurando dentro e fora do tópico especificado para o CI; (4) compilar os dados coletados para fazer um comparativo entre as páginas que tratam sobre CI (seja de forma exclusiva ou não) e o total de páginas dos RI. Foram escolhidos os anos de 2016, 2017 e 2018 por representarem o estado mais atual dos relatórios dessas empresas.

A população de pesquisa são as doze empresas brasileiras participantes do projeto piloto, porém, durante a pesquisa empírica (realizada nos meses de abril a maio de 2019) algumas das empresas ainda não haviam divulgado em seus sites os relatórios de 2018, tendo sido excluídas da base de dados desta pesquisa. Ao final, a amostra foi composta por sete empresas: AES Brasil, BRF, CCR, CPFL, Itaú, Natura, Votorantim; em três anos consecutivos, totalizando 21 relatos, conforme consta na Tabela 1.

As palavras-chave de busca foram escolhidas a partir revisão da literatura acerca de ativos intangíveis e capital intelectual, são elas: "inovação", "pesquisa”, "desenvolvimento", "tecnologia", "patente", "informação" e "conhecimento", adicionados os termos "capital intelectual" e "ativo intelectual". Além de registrar a frequência das palavras citados nos RI, também foi analisado se havia uma relação do capital intelectual, com outros capitais como previsto no framework. 


\section{ARTIGO}

INOVAÇÃO

\section{RESULTADOS E DISCUSSÃO}

Entender o framework do RI foi fundamental para o direcionamento deste estudo, a partir da definição dos princípios norteadores, dos conteúdos que devem ser evidenciados e dos tipos de capitais que evidenciam a criação de valor por parte das empresas, em especial, o capital intelectual.

$\mathrm{Na}$ coleta dos relatos das empresas, notou-se que a AES BRASIL deixou de divulgar os relatórios como AES BRASIL desde 2016 e passou a divulgar somente como AES TIÊTE, ainda assim, não interfere na análise proposta por este estudo, por ser uma empresa do grupo AES BRASIL. Por esse motivo, foi mantida nas análises.

Inicialmente, foi constatado que nem sempre o RI está estruturado por tipos de capital, Os relatos do Itaú, nos três anos pesquisados, apresentam tópicos específicos por tipo de capital, o que facilita a percepção de cada capital e sua importância no conjunto da evidenciação; e apesar da divisão em tópicos, tais relatos apresentam a integração desses capitais, fazerem referências a ações que envolvem mais de um tipo de capital.

Como o reporte do capital intelectual nem sempre se dá em um tópico específico, a Tabela 1, mostra a frequência das palavras e suas variações que remetem ao capital intelectual (ex.: inovação, inovações) e/ou sinônimos (ex.: pesquisa, estudo) no conjunto de cada relato. Foram removidas palavras que encampam outras palavras como "reconhecimento" ou "autoconhecimento" que incorporam a palavra "conhecimento".

Pela Tabela 1, é curioso observar que apesar do capital intelectual ser um dos seis capitais a ser evidenciado a partir da recomendação do framework do RI, foi um dos termos menos encontrados nos relatos pesquisados. Oito relatos não citam nenhuma vez o termo capital intelectual ou seu equivalente (ativo intelectual); outros nove relatos citam no máximo duas vezes.

O termo "gestão de conhecimento" só foi empregado no RI da CPFL de 2018, optando por termos como "informação", "desenvolvimento", "inovação" e "pesquisa". Tal observação também inclui os termos fora do tópico de CI, pois nenhuma das conexões, objetivada pelo framework do RI, foi feita usando o termo capital intelectual.

Os termos relacionados ao capital intelectual mais citados foram: desenvolvimento, informação, inovação e pesquisa. E o conjunto de termos pesquisados de forma mais frequentes nos relatos da Natura, BRF, Votorantim. No geral, o conjunto de termos pesquisados estão bem distribuídos entre os 21 relatos, a maior frequência se deu no relato da 
Natura de 2018 que concentra 8,89\%, e a menor frequência se deu nos seguintes relatos: CCR 2018 (2,63\%), CPFL 2017 (2,63\%) e Itaú de 2017 (2,65\%).

Tabela 1 - Frequência das palavras-chave nos R.I.

\begin{tabular}{|c|c|c|c|c|c|c|c|c|c|c|c|}
\hline \multirow[b]{2}{*}{ Empresas } & \multirow[b]{2}{*}{ Ano } & \multicolumn{8}{|c|}{ Palavras-Chave } & \multirow[b]{2}{*}{$\begin{array}{l}\bar{\pi} \\
\stackrel{0}{0} \\
\qquad\end{array}$} & \multirow[b]{2}{*}{ 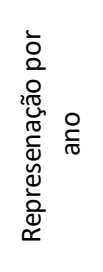 } \\
\hline & & 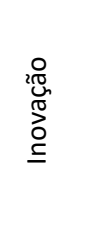 & 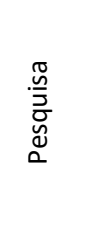 & 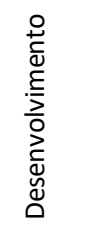 & 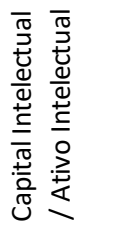 & 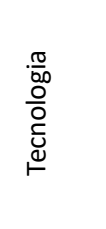 & 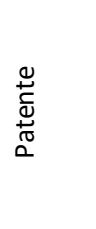 & 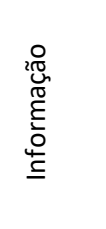 & 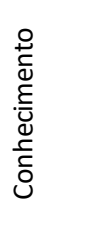 & & \\
\hline \multirow{3}{*}{ AES Brasil } & 2016 & 34 & 19 & 56 & 0 & 15 & 0 & 38 & 9 & 171 & $4,28 \%$ \\
\hline & 2017 & 27 & 21 & 46 & 1 & 16 & 0 & 42 & 11 & 164 & $4,11 \%$ \\
\hline & 2018 & 21 & 16 & 102 & 0 & 21 & 0 & 37 & 11 & 208 & $5,21 \%$ \\
\hline \multirow{3}{*}{ BRF } & 2016 & 87 & 14 & 52 & 0 & 20 & 0 & 35 & 19 & 227 & $5,68 \%$ \\
\hline & 2017 & 33 & 19 & 61 & 4 & 21 & 0 & 53 & 36 & 227 & $5,68 \%$ \\
\hline & 2018 & 28 & 11 & 44 & 3 & 12 & 0 & 50 & 49 & 197 & $4,93 \%$ \\
\hline \multirow{3}{*}{ CCR } & 2016 & 18 & 21 & 45 & 0 & 22 & 2 & 18 & 10 & 136 & $3,40 \%$ \\
\hline & 2017 & 12 & 9 & 37 & 2 & 20 & 0 & 24 & 9 & 113 & $2,83 \%$ \\
\hline & 2018 & 6 & 9 & 46 & 2 & 18 & 0 & 20 & 4 & 105 & $2,63 \%$ \\
\hline \multirow{3}{*}{ CPFL } & 2016 & 11 & 26 & 51 & 0 & 16 & 0 & 32 & 17 & 153 & $3,83 \%$ \\
\hline & 2017 & 21 & 21 & 55 & 1 & 16 & 0 & 66 & 14 & 194 & $4,86 \%$ \\
\hline & 2018 & 6 & 9 & 46 & 2 & 18 & 0 & 20 & 4 & 105 & $2,63 \%$ \\
\hline \multirow{3}{*}{ Itaú } & 2016 & 8 & 10 & 36 & 6 & 29 & 0 & 86 & 10 & 185 & $4,63 \%$ \\
\hline & 2017 & 10 & 8 & 44 & 1 & 25 & 0 & 8 & 10 & 106 & $2,65 \%$ \\
\hline & 2018 & 9 & 12 & 34 & 3 & 47 & 0 & 12 & 12 & 129 & $3,23 \%$ \\
\hline \multirow{3}{*}{ Natura } & 2016 & 57 & 66 & 115 & 0 & 22 & 1 & 31 & 23 & 315 & $7,88 \%$ \\
\hline & 2017 & 41 & 37 & 156 & 0 & 34 & 2 & 40 & 21 & 331 & $8,29 \%$ \\
\hline & 2018 & 78 & 36 & 150 & 0 & 25 & 1 & 50 & 15 & 355 & $8,89 \%$ \\
\hline \multirow{3}{*}{ Votorantim } & 2016 & 35 & 32 & 36 & 1 & 29 & 1 & 38 & 10 & 182 & $4,56 \%$ \\
\hline & 2017 & 34 & 30 & 64 & 2 & 21 & 0 & 35 & 6 & 192 & $4,81 \%$ \\
\hline & 2018 & 36 & 29 & 69 & 2 & 21 & 0 & 36 & 7 & 200 & $5,01 \%$ \\
\hline Total & & 612 & 455 & 1345 & 30 & 468 & 7 & 771 & 307 & 3995 & $100,00 \%$ \\
\hline \multirow{2}{*}{\multicolumn{2}{|c|}{ Representação }} & & & & & & & & & & \\
\hline & & $15,32 \%$ & $11,39 \%$ & $33,67 \%$ & $0,75 \%$ & $11,71 \%$ & $0,18 \%$ & $19,30 \%$ & $7,68 \%$ & $100,00 \%$ & \\
\hline
\end{tabular}

Fonte: Dados da pesquisa, 2019.

Vale destacar que apenas o uso do termo, não necessariamente refere-se ao capital intelectual, por exemplo, a palavra "inovação" é posta em um conceito corporativo no RI da empresa CCR (2018, p. 38) “a inovação corporativa", então para tal uma coleta mais precisa dos dados foi elaborada a Tabela 2 .

Também se ressalta que ao buscar produzir um relato mais sintético, para atender a um dos princípios do framework também pode reduzir a frequência das palavras. Ainda assim, a frequência dos termos pode ser indicador da abordagem de um tema, como demonstrou a ausência do termo capital intelectual (Tabela 1).

A Tabela 2 refere-se à quantidade de páginas que abordam sobre o capital intelectual, através das palavras-chave da Tabela 1 . A Tabela 2 mostra que o tema CI é mais evidenciado fora do tópico específico e esse tipo de evidenciação se dá, em grande parte, por meio dos termos pesquisa e desenvolvimento.

P2P \& INOVAÇÃO, Rio de Janeiro, v. 7, n. 1, p. 227-243, set. 2020/fev. 2021. 


\section{ARTIGO}

INOVAÇÃo

Uma das preocupações desse trabalho foi verificar se o capital intelectual se confunde com o capital humano por possuírem proximidade, porém, não se observou tal confusão, todos os relatórios distinguem tais capitais; sendo que, em grande parte dos RI o termo capital humano foi claramente evidenciado em um tópico específico.

Tabela 2 - Levantamento das páginas que fazem referência ao CI.

\begin{tabular}{|c|c|c|c|c|c|c|}
\hline Empresas & Ano & 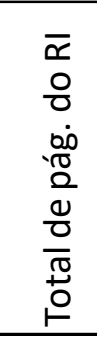 & 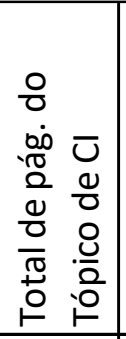 & 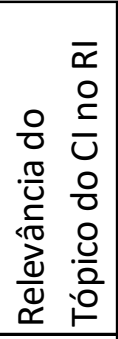 & 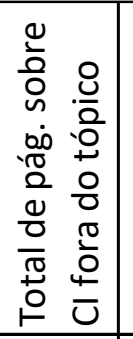 & 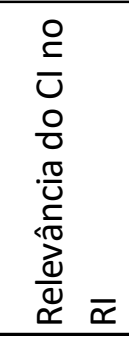 \\
\hline & 2016 & 52 & 1 & $1,92 \%$ & 13 & $26,92 \%$ \\
\hline \multirow[t]{3}{*}{ AES Brasil } & 2017 & 56 & 1 & $1,79 \%$ & 17 & $32,14 \%$ \\
\hline & 2018 & 63 & 1 & $1,59 \%$ & 8 & $14,29 \%$ \\
\hline & 2016 & 204 & 1 & $0,49 \%$ & 8 & $4,41 \%$ \\
\hline \multirow[t]{3}{*}{ BRF } & 2017 & 172 & 1 & $0,58 \%$ & 15 & $9,30 \%$ \\
\hline & 2018 & 126 & 1 & $0,79 \%$ & 4 & $3,97 \%$ \\
\hline & 2016 & 104 & 2 & $1,92 \%$ & 8 & $9,62 \%$ \\
\hline \multirow[t]{3}{*}{ CCR } & 2017 & 43 & 1 & $2,33 \%$ & 2 & $6,98 \%$ \\
\hline & 2018 & 61 & 1 & $1,64 \%$ & 7 & $13,11 \%$ \\
\hline & 2016 & 62 & 6 & $9,68 \%$ & 13 & $30,65 \%$ \\
\hline \multirow[t]{3}{*}{ CPFL } & 2017 & 136 & 6 & $4,41 \%$ & 10 & $11,76 \%$ \\
\hline & 2018 & 108 & 3 & $2,78 \%$ & 12 & $13,89 \%$ \\
\hline & 2016 & 75 & 2 & $2,67 \%$ & 14 & $21,33 \%$ \\
\hline \multirow[t]{3}{*}{ Itaú } & 2017 & 69 & 2 & $2,90 \%$ & 10 & $17,39 \%$ \\
\hline & 2018 & 87 & 1 & $1,15 \%$ & 13 & $16,09 \%$ \\
\hline & 2016 & 150 & 2 & $1,33 \%$ & 18 & $13,33 \%$ \\
\hline \multirow[t]{3}{*}{ Natura } & 2017 & 122 & 1 & $0,82 \%$ & 22 & $18,85 \%$ \\
\hline & 2018 & 125 & 1 & $0,80 \%$ & 21 & $17,60 \%$ \\
\hline & 2016 & 101 & 2 & $1,98 \%$ & 18 & $19,80 \%$ \\
\hline \multirow[t]{2}{*}{ Votorantim } & 2017 & 119 & 8 & $6,72 \%$ & 14 & $18,49 \%$ \\
\hline & 2018 & 104 & 4 & $3,85 \%$ & 14 & $17,31 \%$ \\
\hline \multicolumn{7}{|l|}{$\begin{array}{l}\text { Total de } \\
\text { pág. }\end{array}$} \\
\hline analisadas & & 2139 & 48 & $2,24 \%$ & 261 & $14,45 \%$ \\
\hline
\end{tabular}

Fonte: Dados da pesquisa, 2019.

Apesar de nem todos os relatos terem um tópico exclusivo para o CI (ou termos equivalentes), o citavam no decorrer do RI entrando assim em conformidade com o framework, integrando o capital intelectual aos demais capitais, assim como demonstrado na Tabela 2. Alguns exemplos desses tópicos são: o Itaú, em seus três relatos, usou o termo 
capital intelectual; já a Votorantim Cimentos usou o termo inovação e tecnologia em 2016, inovar para perenizar em 2017 e nosso ecossistema de inovação em 2018.

Quadro 1 - Evidenciação de texto sobre CI nos RI.

\begin{tabular}{||l||l||}
\hline \hline Empresa/Ano & Citação \\
\hline \hline Natura/2016 & $\begin{array}{l}\text { "Entre as principais iniciativas do ano, estão o desenvolvimento do Centro de Pesquisa } \\
\text { Aplicada em Bem-Estar e Comportamento Humano, em parceria com a Fapesp e três } \\
\text { universidades" p. } 38\end{array}$ \\
\hline \hline BRF/2017 & $\begin{array}{l}\text { "As inovações para cada uma delas (veja mais adiante) demonstram que aspectos como } \\
\text { qualidade, saudabilidade e preços adequados podem ser trabalhados a fim de construir } \\
\text { e reforçar, no Brasil, laços com o consumidor." p. } 60\end{array}$ \\
\hline \hline AES/2018 & $\begin{array}{l}\text { "De acordo com o Programa de P\&D da Aneel, nossos investimentos regulados devem } \\
\text { ser realizados em projetos vinculados à inovação. Em 2018, destacamos as seguintes } \\
\text { iniciativas, por seu caráter inovador e contribuição ambiental:" p. 32 } \\
\text { "Virtual Power Plant (VPP) } \\
\text { Previsão de investimento: R\$ 4,5 milhões } \\
\text { Prazo: } 17 \text { meses } \\
\text { Descrição do projeto: Virtual Power Plant AES com Foco em Agregação de Grandes } \\
\text { Clientes e Mercado Energético: Desenvolvimento de Plataforma, Implantação de Piloto } \\
\text { e Modelagem de Negócios. } \\
\text { Produto: Plataforma com foco em agregação e alavancagem da flexibilização de } \\
\text { cargas, visando à viabilização da participação em dois tipos de mercado: mercado } \\
\text { interno, para otimização do preço da geraçâo do consumo; e mercado externo, pata } \\
\text { provisão de serviços a distintas entidades do setor" }\end{array}$ \\
\hline
\end{tabular}

Fonte: Dados da pesquisa, 2019.

Muitos desses RI consideravam, em seus tópicos específicos de CI, apenas os conhecimentos obtidos de forma externa, como exemplo a Natura (2017) fala em seu tópico de CI somente sobre um programa elaborado em 2016, que dá sequência aos projetos que adotam o sistema agroflorestal (SAF), entretanto não fala da "Pesquisa de engajamento", por tratar-se de uma pesquisa interna. No Quadro 1 foram destacadas citações dos RI que evidencia o CI de forma textual.

A primeira citação evidencia a parceria com universidades para pesquisas para o Bemestar e comportamento humano, sendo assim um conhecimento adquiro pela empresa que será convertido em benefícios ativos, sendo assim um investimento em CI, a segundo citação se refere a inovações de produtos, sendo essas mudanças físicas e de marketing, a terceira é um parágrafo anterior a lista de projeto e em seguida um desses projetos, onde é evidenciado o nome do projeto, a previsão monetária do investimento, uma descrição de como será realizado o projeto e o produto resultante desse projeto. Tais citações textuais são encontradas em todos 


\section{יבי}

\section{ARTIGO}

INOVAÇÃO

os RI em quantidade. No Quadro 2 são demonstradas as citações numéricas dos investimentos.

Quadro 2 - Evidenciação monetária do CI nos RI.

\begin{tabular}{||l||l||}
\hline Empresa/Ano & Citação \\
\hline \hline AES/2016 & "No último ano, investimos um total de R\$ 6,7 milhões em P\&D (Pesquisa e \\
& desenvolvimento)" p. 16 \\
& "O projeto receberá, no total, investimentos da ordem de R \$ 5,1 milhões.” p. 16 \\
\hline \hline CPFL/2017 & “・R \$ 44,5 milhões em P\&D \\
& $\bullet R \$ 2,7$ milhões em Programas de Requalificação" p. 36 \\
\hline \hline BRF/2018 & "R \$ 53,5 milhões investidos em P\&D” p. 49 \\
\hline
\end{tabular}

Fonte: Dados da pesquisa, 2019.

Possui poucos RI que evidenciam monetariamente o CI, deixando de obedecer ao princípio da materialidade descrito no Framework.

Segundo o framework, os RI possuem sete princípios básicos, entretanto, para os propósitos desta pesquisa, foram avaliados quatro desses princípios, a saber: (1) conectividade, (2) completude, (3) concisão e (4) coerência.

Em consideração aos princípios do RI previstos no framework, em especial, o da conectividade, foi constatado que os hiperlinks não estão presentes no RI como um todo, porém, existem atalhos que com simples clicks direcionam o leitor até informações relevantes dentro do próprio RI. Nos tópicos de CI não é muito diferente, porém, em citações fora do tópico, não há direcionamento para o tópico, que trata de capital intelectual, com esses clicks.

Quanto ao princípio da completude, muitas tiveram sua avaliação mediana, pois apesar das informações serem bem evidenciadas nos princípios básicos, algumas informações que não ocupariam muito espaço não foram evidenciadas nessas empresas, com exceção do Itaú, da Votorantim e da Natura, que evidenciaram monetariamente o quanto foi gasto em pesquisa.

Outro princípio que foi avaliado é o princípio da concisão quanto ao CI, a maioria dos relatos evidenciam seus tópicos de CI com uma única página, por tanto, o que mais faz diferencia nessa concisão é o número de páginas que o RI possui.

Finalmente, em relação ao princípio da coerência, constatou-se que este é o princípio que mais destaca diferenças nos RI. A maior parte dos RI tem coerência, pela sua linguagem ao tratar do CI, mas não fazem um comparativo ao longo do tempo, como aconselha o framework, com exceção do Itaú e da Votorantim, que não somente fazem o comparativo, como também fazem antecipações de cenários. 
Durante a análise, constatou-se que as empresas no decorrer de 2016 a 2018, estão divulgando o CI sempre da mesma forma, com alterações mínimas em suas estruturas.

\section{CONSIDERAÇÕES FINAIS}

Este estudo se propôs a responder como está sendo evidenciado o capital intelectual no Relato Integrado das empresas brasileiras participantes do programa piloto, no período de 2016 a 2018, e, dessa forma, pode-se avaliar que sim, o capital intelectual está sendo evidenciado nos Relatos Integrados.

Conclui-se, que todos os relatos cumpriram os requisitos básicos de evidenciação esperados, e descrevem o capital intelectual de forma menos quantitativa (monetária) e mais qualitativa, ainda que alguns sejam mais dispersos que outros, necessitando maior interação com outros relatórios da organização, além da necessidade de evidenciar os planos futuros de gestão do capital intelectual.

Os resultados evidenciaram conectividade de informações do próprio relato em todas as empresas, mas falham na conexão aos demais relatórios contábeis (Financeiros, de Sustentabilidade, de Governança Corporativa e da Administração); no quesito completude, os relatos se apresentam completos, com exceções em valores monetários distintos quanto a cada tipo de investimento; no quesito concisão, há divergências na representatividade do capital intelectual em relação ao total de informações divulgadas; e, em relação ao quesito coerência, todos apresentaram coerência das informações divulgadas em relação a anos anteriores, mas, apenas duas empresas projetam o capital intelectual no futuro.

Nesse sentido, de modo geral a completude dos relatos foi avaliada como satisfatória, apresentando uma concisão variada de empresa para empresa. A coerência é um princípio bem avaliado, com a maioria tendo um desempenho considerado bom.

Este trabalho teve limitações durante sua execução: não foi possível pesquisar todas as empresas brasileiras do projeto piloto, mas apesar de não ter pesquisado as doze empresas brasileiras do programa piloto, a amostra é representativa 58,33\%. Durante as análises dos RI, não se constatou nenhuma grande evolução na evidenciação do CI, uma vez que as empresas se limitaram a sempre evidenciar apenas suas pesquisas externas. Entretanto, acredita-se que o período pesquisado da amostra foi muito curto para que haja mudanças significativas nesses RI. 
Com base nas conclusões desse artigo, abre-se a possibilidade de aprofundamento: pesquisas que englobem empresas estrangeiras; pesquisas com outros tipos de capitais do framework, ou ainda a análise da evolução longitudinal da evidenciação do capital intelectual. 


\section{REFERÊNCIAS}

ALVES, Nadson Jaime Ferreira et al. Relato integrado e o formato da informação financeira para evidenciar a criação de valor das empresas do Programa Piloto. Revista Evidenciação Contábil \& Finanças, v. 5, n. 3, p. 99-122, 2017a. Disponível em: https://periodicos.ufpb.br/ ojs2/index.php/recfin/article/view/34070/18279. Acesso em: 12 ago. 2020.

ALVES, Nadson Jaime Ferreira. Tese-Relato Integrado: Potencial de significação da linguagem visual das informações financeiras e não financeiras nos relatos das empresas do Programa Piloto no Brasil. 2017. Tese (Doutorado em Administração) - Universidade Municipal de São Caetano do Sul, São Caetano do Sul, 2017b.

ANTUNES, Maria Thereza Pompa; MARTINS, Eliseu. Capital intelectual: verdades e mitos. Revista Contabilidade \& Finanças, v. 13, n. 29, p. 41-54, 2002.

ANTUNES, Maria Thereza Pompa; MARTINS, Eliseu. Capital intelectual: seu entendimento e seus impactos no desempenho de grandes empresas brasileiras. Revista de administração e Contabilidade da Unisinos, v. 4, n. 1, p. 5-21, 2007a.

ANTUNES, Maria Thereza Pompa; MARTINS, Eliseu. Gerenciando o capital intelectual: uma proposta baseada na controladoria de grandes empresas brasileiras. Porto Alegre. Revista Eletrônica de Administração, v. 13, n. 1, 2007b. Disponível em: https://seer.ufrgs.br/read/art icle/view/39905/25440. Acesso em: 20 ago. 2020.

BONACIM, Carlos Alberto Grespan; ARAÚJO, Adriana Maria Procópio de. Influência do capital intelectual na avaliação de desempenho aplicada ao setor hospitalar. Ciência \& Saúde Coletiva, v. 15, p. 1249-1261, 2010.

BRASIL. Lei Ordinária n. 11.638, de 28 de dezembro de 2007: Altera e revoga dispositivos da Lei no 6.404, de 15 de dezembro de 1976, e da Lei no 6.385, de 7 de dezembro de 1976, e estende às sociedades de grande porte disposições relativas à elaboração e divulgação de demonstrações financeiras. Diário Oficial da União, Brasília-DF, 28 de dez. 2007.

CARVALHO, Luiz Nelson Guedes de; KASSAI, José Roberto. A nova revolução contábil. Revista Fipecafi, n. 1, p. 21-34, 2014.

COMITÊ DE PRONUNCIAMENTOS CONTÁBEIS. Pronunciamento Técnico CPC 04Ativo Intangível. 2010. Disponível em: http://www.cpc.org.br/CPC/Documentos-Emitidos/Pr onunciamentos/Pronunciamento?Id=35. Acesso em: 25 ago. 2020.

GALLON, Alessandra Vasconcelos et al. Um estudo reflexivo da produção científica em capital intelectual. Revista de Administração Mackenzie, v. 9, n. 4, 2008.

ILVA FILHO, Gilberto Magalhães da; BARBOSA, Mayara Bezerra; PEREIRA, Tarso Rocha Lula. Adoção das Normas Internacionais de Contabilidade: Análise do Impacto nos Indicadores Econômico-Financeiros no Setor de Energia Elétrica. Revista de Auditoria Governança e Contabilidade, v. 7, n. 29, 2019.

INTERNATIONAL INTEGRATED REPORTING COUNCIL. A estrutura internacional para relato integrado: International Reporting <IR>. Londres: IIRC, 2013. Disponível em: 
http://integratedreporting.org/wp-content/uploads/2015/03/13-12-08-THE-INTERNATIONA L-IR-FRAMEWORK-Portugese-final-1.pdf. Acesso em: 05 jun. 2019.

LAVA Jato: cronologia da investigação sobre escândalo de corrupção da Petrobras. Estado de Minas, Belo Horizonte, 2018. Disponível em: https://www.em.com.br/app/noticia/internac ional/2018/04/06/interna_internacional,949445/lava-jato-cronologia-da-investigacao-sobreescandalo-de-corrupcao-da.shtml. Acesso em: 10 jun. 2019.

MACIEL, Paula Álvares. Relato integrado: análise da evolução da estrutura conceitual e sua aplicação nos relatórios das empresas no Brasil. 2015. 173 f. Dissertação (Mestrado em Ciências Contábeis) - Universidade Federal do Rio de Janeiro, Rio de Janeiro, 2015.

MARCONI, Marina de Andrade; LAKATOS, Eva Marina. Metodologia Científica. 4. ed. São Paulo: Editora Atlas S.A, 2004.

PEREZ, Marcelo Monteiro; FAMÁ, Rubens. Ativos intangíveis e o desempenho empresarial. Revista Contabilidade \& Finanças, v. 17, n. 40, p. 7-24, 2006.

SANTOS, José Luiz dos et al. A importância do capital intelectual na sociedade do conhecimento. ConTexto (Porto Alegre). v. 8, n. 14 (2. sem. 2008), p. 1-16, 2008.

SINDICATO NACIONAL DA INDÚSTRIA DO CIMENTO. Relatório Integrado da Votorantim Cimentos de 2016 é eleito melhor do mundo pelo Conselho Empresarial Mundial para o Desenvolvimento Sustentável 2017. Disponível em: http://snic.org.br/notici as-ver.php?id=13. Acesso em: 10 jun. 2019.

SKANDIA, GRUPO. Visualizando o capital intelectual na Skandia. Suplemento do Relatório Anual. Estocolmo, 1994.

TOMO, Ocean. Components of S\&P 500 market value. Retrieved June, v. 5, p. 2015. Disponível em: https://www.oceantomo.com/intangible-asset-market-value-study/. Acesso em: 07 jun. 2019.

ZARO, Elise Soerger et al. Relatórios Integrados: Evolução da Evidenciação do desempenho das Organizações. In: ENGEMA, 16, São Paulo, 01, 02 e 03 de dezembro de 2014. Anais [...]. São Paulo, 2014. 